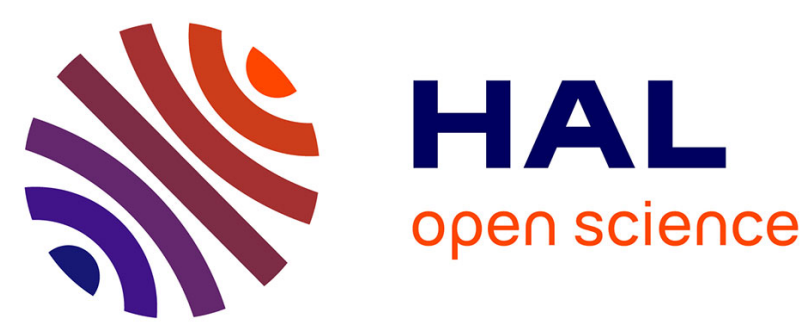

\title{
EVOLUTION OF OXYGEN ISOTOPIC COMPOSITION IN THE INNER SOLAR NEBULA
}

\author{
Alexander N Krot, Ian D Hutcheon, Hisayoshi Yurimoto, Jeffrey N Cuzzi, \\ Kevin Mckeegan, Edward R D Scott, Guy Libourel, Marc Chaussidon, Jérôme \\ Aléon, Michael I Petaev
}

\section{To cite this version:}

Alexander N Krot, Ian D Hutcheon, Hisayoshi Yurimoto, Jeffrey N Cuzzi, Kevin Mckeegan, et al.. EVOLUTION OF OXYGEN ISOTOPIC COMPOSITION IN THE INNER SOLAR NEBULA. The Astrophysical Journal, 2005, 622 (2), pp.1333-1342. insu-01881986

\section{HAL Id: insu-01881986 https://hal-insu.archives-ouvertes.fr/insu-01881986}

Submitted on 26 Sep 2018

HAL is a multi-disciplinary open access archive for the deposit and dissemination of scientific research documents, whether they are published or not. The documents may come from teaching and research institutions in France or abroad, or from public or private research centers.
L'archive ouverte pluridisciplinaire HAL, est destinée au dépôt et à la diffusion de documents scientifiques de niveau recherche, publiés ou non, émanant des établissements d'enseignement et de recherche français ou étrangers, des laboratoires publics ou privés. 
The Astrophysical Journal, 622:1333-1342, 2005 April 1

(C) 2005. The American Astronomical Society. All rights reserved. Printed in U.S.A.

\title{
EVOLUTION OF OXYGEN ISOTOPIC COMPOSITION IN THE INNER SOLAR NEBULA
}

\author{
Alexander N. Krot, ${ }^{1}$ Ian D. Hutcheon, ${ }^{2}$ Hisayoshi Yurimoto, ${ }^{3}$ Jeffrey N. Cuzzi, ${ }^{4}$ Kevin D. McKeegan, ${ }^{5}$ \\ Edward R. D. Scott, ${ }^{1}$ Guy Libourel, ${ }^{6,7}$ Marc Chaussidon, ${ }^{6}$ Jerome Aléon, $^{6}$ and Michael I. Petaev ${ }^{8}$ \\ Received 2004 September 27; accepted 2004 December 17
}

\begin{abstract}
Changes in the chemical and isotopic composition of the solar nebula with time are reflected in the properties of different constituents that are preserved in chondritic meteorites. CR-group carbonaceous chondrites are among the most primitive of all chondrite types and must have preserved solar nebula records largely unchanged. We have analyzed the oxygen and magnesium isotopes in a range of the CR constituents of different formation temperatures and ages, including refractory inclusions and chondrules of various types. The results provide new constraints on the time variation of the oxygen isotopic composition of the inner $(<5 \mathrm{AU})$ solar nebula - the region where refractory inclusions and chondrules most likely formed. A chronology based on the decay of short-lived ${ }^{26} \mathrm{Al}$ $\left(t_{1 / 2} \sim 0.73 \mathrm{Myr}\right)$ indicates that the inner solar nebula gas was ${ }^{16} \mathrm{O}$-rich when refractory inclusions formed, but less than 0.8 Myr later, gas in the inner solar nebula became ${ }^{16} \mathrm{O}$-poor, and this state persisted at least until CR chondrules formed $\sim 1-2$ Myr later. We suggest that the inner solar nebula became ${ }^{16} \mathrm{O}$-poor because meter-sized icy bodies, which were enriched in ${ }^{17} \mathrm{O}$ and ${ }^{18} \mathrm{O}$ as a result of isotopic self-shielding during the ultraviolet photodissociation of $\mathrm{CO}$ in the protosolar molecular cloud or protoplanetary disk, agglomerated outside the snow line, drifted rapidly toward the Sun, and evaporated at the snow line. This led to significant enrichment in ${ }^{16} \mathrm{O}$-depleted water, which then spread through the inner solar system. Astronomical studies of the spatial and temporal variations of water abundance in protoplanetary disks may clarify these processes.
\end{abstract}

Subject headings: meteors, meteoroids - nuclear reactions, nucleosynthesis, abundances planetary systems: formation — solar system: formation

\section{INTRODUCTION}

Chondritic meteorites are the oldest rocks formed in the early solar system. They consist of three major components: refractory inclusions (Ca-Al-rich inclusions [CAIs] and amoeboid olivine aggregates $[\mathrm{AOAs}]$ ), chondrules, and fine-grained matrix (Scott \& Krot 2003). CAIs are irregularly shaped or rounded objects that range in size from less than $100 \mu \mathrm{m}$ to over $1 \mathrm{~cm}$ and are composed mostly of oxides and silicates of calcium, aluminum, titanium, and magnesium, such as corundum $\left(\mathrm{Al}_{2} \mathrm{O}_{3}\right)$, hibonite $\left(\mathrm{CaAl}_{12} \mathrm{O}_{19}\right)$, grossite $\left(\mathrm{CaAl}_{4} \mathrm{O}_{7}\right)$, perovskite $\left(\mathrm{CaTiO}_{3}\right)$, spinel $\left(\mathrm{MgAl}_{2} \mathrm{O}_{4}\right)$, Al-Ti pyroxene (a solid solution of $\mathrm{CaTi}^{+4} \mathrm{Al}_{2} \mathrm{O}_{6}, \mathrm{CaTi}^{+3} \mathrm{AlSiO}_{6}$, $\mathrm{CaAl}_{2} \mathrm{SiO}_{6}$, and $\mathrm{CaMgSi}_{2} \mathrm{O}_{6}$ ), melilite (a solid solution of $\mathrm{Ca}_{2} \mathrm{MgSi}_{2} \mathrm{O}_{7}$ and $\left.\mathrm{Ca}_{2} \mathrm{Al}_{2} \mathrm{SiO}_{7}\right)$, and anorthite $\left(\mathrm{CaAl}_{2} \mathrm{Si}_{2} \mathrm{O}_{8}\right)$. AOAs are physical aggregates of individual condensate particlesforsterite $\left(\mathrm{Mg}_{2} \mathrm{SiO}_{4}\right), \mathrm{Fe}-\mathrm{Ni}$ metal, and CAIs composed of spinel, anorthite, and Al-Ti pyroxene. Chondrules are igneous, rounded objects, $0.01-10 \mathrm{~mm}$ in size, composed largely of ferromag-

\footnotetext{
${ }^{1}$ Hawai'i Institute of Geophysics and Planetology, School of Ocean and Earth Science and Technology, University of Hawai ‘ $i$ at Mānoa, 1680 East West Road, Honolulu, HI 96822; sasha@higp.hawaii.edu.

${ }^{2}$ Lawrence Livermore National Laboratory, 7000 East Avenue, Livermore, CA 94451 .

3 Department of Earth and Planetary Sciences, Tokyo Institute of Technology, 2-12-1 O-okayama, Meguro-ku, Tokyo 152-8551, Japan.

${ }^{4}$ Space Science and Astrobiology Division, NASA Ames Research Center, Moffett Field, CA 94035.

5 Department of Earth and Space Sciences, UCLA, Los Angeles, CA 90095-1567.

${ }^{6}$ Centre de Recherches Pétrographiques et Géochimiques, UPR 2300, CNRS, B.P. 20, F-54501 Vandoeuvre lès Nancy, France.

${ }^{7}$ Ecole Nationale Supérieure de Géologie, Institut National Polytechnique de Lorraine, B.P. 40, F-54501 Vandoeuvre lès Nancy, France.

${ }^{8}$ Harvard-Smithsonian Center for Astrophysics and Department of Earth and Planetary Sciences, Harvard University, 20 Oxford Street, Cambridge, MA 02138.
}

nesian olivine $\left(\mathrm{Mg}_{2-x} \mathrm{Fe}_{x} \mathrm{SiO}_{4}\right)$ and pyroxene $\left(\mathrm{Mg}_{1-x} \mathrm{Fe}_{x} \mathrm{SiO}_{3}\right.$, where $1<x<0$ ), Fe-Ni metal, and glassy or microcrystalline mesostasis. Chondrules dominated by olivine and pyroxene phenocrysts (grains crystallized from a host chondrule melt) are called porphyritic. Some few percent of all chondrules are known to be unusually rich in aluminum, and these often contain relict (unmelted objects that did not crystallize from a host-chondrule melt) refractory inclusions (Krot \& Keil 2002; Itoh et al. 2002; Krot et al. 2001, 2002a, 2004a). Matrix material is an aggregate of mineral grains, $10 \mathrm{~nm}$ to $5 \mu \mathrm{m}$ in size, that surrounds refractory inclusions and chondrules and fills in the interstices between them; in primitive chondrites, matrix is made largely of magnesian olivine and pyroxene and amorphous ferromagnesian silicate particles (see, e.g., Greshake 1997).

Chondrules and refractory inclusions are believed to have formed during transient heating events in the inner $(<5 \mathrm{AU})$ solar nebula (see, e.g., Cassen 2001; Desch \& Connolly 2002; MacPherson 2003). Evaporation and condensation appear to have been the dominant processes during formation of refractory inclusions; subsequently, some CAIs experienced melting to various degrees (MacPherson 2003). Multiple episodes of melting of preexisting solids accompanied by evaporation and recondensation are believed to have been the dominant processes during chondrule formation (Desch \& Connolly 2002; Scott \& Krot 2003). Matrices are chemically complementary to chondrules and may have largely experienced extensive evaporation and recondensation during chondrule formation (Kong 1999; Klerner \& Palme 2000; Scott \& Krot 2003; Bland et al. 2004). Mineralogical, chemical, and isotopic studies of chondritic components provide important constraints on the physical and chemical processes, physicochemical conditions, chemical and isotopic compositions, and the lifetime of the protoplanetary disk (e.g., Krot et al. 2000, 2002b; Scott \& Krot 2003; Russell et al. 2005). 
In this paper, we address the origin and evolution of the oxygen isotopic composition of the inner solar nebula using oxygen and magnesium isotopic compositions of refractory inclusions and chondrules in the CR-group carbonaceous chondrites. CR chondrites are among the most primitive chondrite groups (Krot et al. 2002c) and largely escaped the thermal metamorphism and hydrothermal alteration on their parent asteroid (or asteroids) that disturbed nebular records of both oxygen and magnesium isotopic compositions in the $\mathrm{CV}$ and metamorphosed $\mathrm{CO}$ chondrites (e.g., Krot et al. 1998; Wasson et al. 2001; Yurimoto et al. 2000; McKeegan et al. 2004). CR chondrites did experience mild, lowtemperature aqueous alteration, but this appears not to have affected the oxygen and magnesium isotopic compositions of their refractory inclusions and chondrules (Marhas et al. 2000, 2001; Aléon et al. 2002; Krot et al. 2004b, 2004d).

\section{OXYGEN ISOTOPIC RESERVOIRS IN THE INNER SOLAR NEBULA}

On an oxygen three-isotope diagram $\left(\delta^{18} \mathrm{O}\right.$ vs. $\delta^{17} \mathrm{O}$, where $\left.\delta^{\{17,18\}} \mathrm{O}=\left[\left(\{17,18\} \mathrm{O} /{ }^{16} \mathrm{O}\right)_{\text {sample }} /\left({ }^{\{17,18\}} \mathrm{O} /{ }^{16} \mathrm{O}\right)_{\mathrm{SMOW}}-1\right] \times 10^{3}\right)$; SMOW is Standard Mean Ocean Water), compositions of CAIs, AOAs, and chondrules in primitive chondrites generally plot along a line of slope $\sim 1$ and show a large range of $\Delta^{17} \mathrm{O}$ (from less than -20 to +5 per mill [\%o], where $\Delta^{17} \mathrm{O}=\delta^{17} \mathrm{O}-0.52 \delta^{18} \mathrm{O}$; e.g., Clayton et al. 1977; Clayton 1993; McKeegan \& Leshin 2001). These mass-independent variations most likely resulted from mixing of ${ }^{16} \mathrm{O}$-rich and ${ }^{16} \mathrm{O}$-poor materials in the solar nebula (e.g., Clayton 1993). By contrast, mass-dependent variations, resulting from differences in isotopic masses during chemical and physical processes, plot along a line of slope $\sim \frac{1}{2}$ (McKeegan $\&$ Leshin 2001).

The existence of an ${ }^{16} \mathrm{O}$-rich gaseous reservoir in the inner solar nebula has been inferred from the ${ }^{16} \mathrm{O}$-rich $\left(\Delta^{17} \mathrm{O}<-20 \%\right)$ compositions of refractory solar nebula condensates, such as AOAs, forsterite-rich accretionary rims around CAIs, and finegrained, spinel-rich CAIs with group II rare earth element (REE) patterns (volatility-fractionated REE patterns indicating condensation from a gas from which more refractory REE has already been removed; Scott \& Krot 2001; Krot et al. 2002a; Aléon et al. 2004). An ${ }^{16} \mathrm{O}$-poor gaseous reservoir can be inferred from most chondrules, which are consistently ${ }^{16} \mathrm{O}$-depleted compared with AOAs and most CAIs (e.g., Clayton 1993; Maruyama et al. 1999; Krot et al. 2004b), and from the ${ }^{16} \mathrm{O}$-poor compositions of aqueously formed secondary minerals in chondrites (Choi et al. 1998). Although few presolar ${ }^{16} \mathrm{O}$-rich solids in meteorites are known to have survived evaporation (Nittler et al. 1997, 1998), their existence has been inferred (Scott \& Krot 2001) from (1) ${ }^{16} \mathrm{O}-$ rich compositions of platy hibonite crystals (PLACs) and some FUN (fractionation and unknown nuclear anomalies) CAIs that are considered to be evaporative residues of the initial solar nebula dust (Fahey et al. 1987; Brigham et al. 1988; Ireland 1990; Wood 1998; Lee \& Shen 2001; Goswami et al. 2001), and (2) from an ${ }^{16} \mathrm{O}$-rich magnesian chondrule, which has been interpreted as a solidified melt of this dust (Kobayashi et al. 2003).

Previous models assumed the existence of ${ }^{16} \mathrm{O}$-rich solids and ${ }^{16} \mathrm{O}$-poor gas and invoked solid-gas fractionation to produce the ${ }^{16} \mathrm{O}$-rich and ${ }^{16} \mathrm{O}$-poor solar nebula regions (Scott \& Krot 2001; Krot et al. 2002b; Itoh \& Yurimoto 2003). The ultimate source of the mass-independent oxygen-isotope fractionation was ascribed to unknown processes, either presolar (Clayton et al. 1977; Thiemens \& Heidenreich 1983; Clayton 1993; Scott \& Krot 2001) or solar (Thiemens \& Heidenreich 1983; Thiemens 1996). This observed mass-independent fractionation of oxygen isotopes has most recently been attributed to isotopic self-shielding during UV photolysis of $\mathrm{CO}$ in an initially ${ }^{16} \mathrm{O}-$ rich $\left(\Delta^{17} \mathrm{O} \sim\right.$ $-25 \%$ ) protoplanetary disk (Kitamura \& Shimizu 1983; Clayton 2002; Lyons \& Young 2004) or parent molecular cloud (Yurimoto \& Kuramoto 2004). According to these models, the UV photolysis preferentially dissociates $\mathrm{C}^{17} \mathrm{O}$ and $\mathrm{C}^{18} \mathrm{O}$ in illuminated zones of the protoplanetary disk (most likely the very uppermost, rarefied vertical layer) or the parent molecular cloud. If this process occurs in the stability field of water ice, the released atomic ${ }^{17} \mathrm{O}$ and ${ }^{18} \mathrm{O}$ are rapidly incorporated into water ice, while the residual $\mathrm{CO}$ gas becomes enriched in ${ }^{16} \mathrm{O}$ (Yurimoto \& Kuramoto 2004). Subsequent enhancement of ${ }^{16} \mathrm{O}$-depleted water ice relative to ${ }^{16} \mathrm{O}$-enriched $\mathrm{CO}$ gas in the midplane of the protoplanetary disk, followed by ice evaporation, can in principle result in generation of an ${ }^{16} \mathrm{O}$-poor gaseous region.

The history of oxygen isotopic variations in the inner solar nebula gas may have been recorded by igneous CAIs and chondrules that appear to have experienced oxygen isotopic exchange with the surrounding gas during melting (Yu et al. 1995; Yurimoto et al. 1998; Maruyama et al. 1999; Aléon et al. 2002; Itoh \& Yurimoto 2003; Krot et al. 2004b, 2004c). The timescales of CAI and chondrule formation can be deduced from their short-lived $\left({ }^{26} \mathrm{Al}-{ }^{26} \mathrm{Mg}\right)$ and long-lived $\left({ }^{207} \mathrm{~Pb}-{ }^{206} \mathrm{~Pb}\right)$ isotopic systematics (MacPherson et al. 1995; Amelin et al. 2002, 2004; Russell et al. 2005). Although igneous CAIs and chondrules with heterogeneous oxygen isotopic compositions are common in previously studied $\mathrm{CV}$ chondrites, the nature and timing of oxygen isotopic exchange affecting $\mathrm{CV}$ chondrite components are controversial subjects because of ubiquitous secondary alteration (e.g., Krot et al. 1998). This motivated our study of CR chondrites.

\section{CHRONOLOGY OF REFRACTORY INCLUSIONS AND CHONDRULES}

The average ${ }^{207} \mathrm{~Pb}-{ }^{206} \mathrm{~Pb}$ age of two CAIs from Efremovka (CV) is $4567.2 \pm 0.6 \mathrm{Myr}$ (Amelin et al. 2002). The ${ }^{207} \mathrm{~Pb}-{ }^{206} \mathrm{~Pb}$ ages of chondrules range from $4566.7 \pm 1.0 \mathrm{Myr}$ for Allende (CV) to $4564.7 \pm 0.7 \mathrm{Myr}$ for Acfer $059(\mathrm{CR})$ to $4562.7 \pm 0.5 \mathrm{Myr}$ for Gujba (CB, an unusual, metal-rich chondrite) (Amelin et al. 2004). These observations suggest that chondrule formation started shortly after or perhaps even contemporaneously with CAI formation and lasted for at least $4.5 \pm 1.1 \mathrm{Myr}$. The duration of CAI formation remains unknown, but it could be as short as $0.5 \mathrm{Myr}$, based on ${ }^{26} \mathrm{Al}-{ }^{26} \mathrm{Mg}$ systematics (Bizzarro et al. 2004).

Most CAIs in primitive chondrites have an initial ${ }^{26} \mathrm{Al} /{ }^{27} \mathrm{Al}$ ratio $\left[\left({ }^{26} \mathrm{Al} /{ }^{27} \mathrm{Al}\right)_{0}\right]$ of $5 \times 10^{-5}$, commonly referred to as "canonical," which represents the initial abundance of ${ }^{26} \mathrm{Al}$ in the solar nebula (MacPherson et al. 1995; Russell et al. 2005), or just in the CAI-forming region, possibly near the proto-Sun (Shu et al. 1996). ${ }^{9}$ The rare exceptions include PLACs, FUN CAIs, and grossite-rich and hibonite-rich CAIs from $\mathrm{CH}$ carbonaceous chondrites, which show no evidence for live ${ }^{26} \mathrm{Al}$. FUN CAIs and PLACs have been interpreted as the earliest products in the solar system, having formed prior to injection and homogenization of ${ }^{26} \mathrm{Al}$ (Sahijpal et al. 1998). The lack of ${ }^{26} \mathrm{Al}$ in $\mathrm{CH}$ CAIs remains unexplained. Because the vast majority of CAIs in primitive (unmetamorphosed) chondrites are characterized by the canonical $\left({ }^{26} \mathrm{Al} /{ }^{27} \mathrm{Al}\right)_{0}$ ratio, it is reasonable to assume that igneous CAIs in primitive chondrites also formed by the melting of inclusions having initially canonical $\left({ }^{26} \mathrm{Al} /{ }^{27} \mathrm{Al}\right)_{0}$ ratios. In contrast, the vast

${ }^{9}$ Galy et al. (2004) reported an $\left({ }^{26} \mathrm{Al} /{ }^{27} \mathrm{Al}\right)_{0}$ ratio of $(6.78 \pm 0.85) \times 10^{-5}$ in bulk CAIs from $\mathrm{CV}$ chondrites, and they interpreted this ratio to represent the time of segregation of the CV proto-CAIs from the rest of the solar nebula as $\sim 0.4$ Myr before the last melting of the CV CAIs that is recorded by a canonical ${ }^{26} \mathrm{Al} /{ }^{27} \mathrm{Al}$ ratio of $5 \times 10^{-5}$. 
majority of chondrules have much lower $\left({ }^{26} \mathrm{Al} /{ }^{27} \mathrm{Al}\right)_{0}$ ratios $\left(\leq 1.5 \times 10^{-5}\right.$; Russell et al. 1996; Kita et al. 2000; Marhas et al. $2000)$. High $\left({ }^{26} \mathrm{Al} /{ }^{27} \mathrm{Al}\right)_{0}$ ratios have recently been reported in several magnesian chondrules from the CV chondrite Allende, based on their bulk magnesium-isotope measurements (Bizzarro et al. 2004).

The difference in $\left({ }^{26} \mathrm{Al} /{ }^{27} \mathrm{Al}\right)_{0}$ ratios between CAIs and most chondrules suggests an age difference of at least 1-2 Myr between the crystallization ages of CAIs and the majority of chondrules (MacPherson et al. 1995; Russell et al. 1996; Kita et al. 2000; Marhas et al. 2000; Russell et al. 2005). This chronological interpretation of ${ }^{26} \mathrm{Al}^{26} \mathrm{Mg}$ systematics is based on the assumption that ${ }^{26} \mathrm{Al}$ had a stellar origin and was injected and homogenized in the solar nebula over a timescale that was short compared with its half-life $\left(t_{1 / 2} \sim 0.7 \mathrm{Myr}\right)$ (e.g., MacPherson et al. 1995). We note that, if interpreted chronologically, the high $\left({ }^{26} \mathrm{Al} /{ }^{27} \mathrm{Al}\right)_{0}$ ratios inferred from bulk magnesium-isotope measurements of the Allende chondrules (Bizzarro et al. 2004) may date the time for the formation of chondrule precursor materials, not the time of chondrule melting; the latter can be inferred from internal aluminum-magnesium isochrons, which have not been measured in these chondrules yet.

The alternative, nonchronological interpretation of ${ }^{26} \mathrm{Al}-{ }^{26} \mathrm{Mg}$ systematics involves a local origin of ${ }^{26} \mathrm{Al}$ by energetic-particle irradiation near the proto-Sun, resulting in a radial heterogeneity of the ${ }^{26} \mathrm{Al}$ distribution (e.g., Gounelle et al. 2001). Although the detection in CAIs of short-lived radionuclides that can be produced by nuclear spallation reactions and not in the stars- ${ }^{10} \mathrm{Be}$ $\left(t_{1 / 2} \sim 1.5 \mathrm{Myr} ;\right.$ McKeegan et al. 2000$)$ and possibly ${ }^{7} \mathrm{Be}\left(t_{1 / 2} \sim\right.$ 52 days; Chaussidon et al. 2002, 2004) - may indicate that CAIs or their precursors experienced irradiation by energetic particles, this mechanism remains problematic for ${ }^{26} \mathrm{Al}$ (McKeegan et al. 2000). At the same time, a stellar origin for ${ }^{26} \mathrm{Al}$ is consistent with (1) correlated abundances of ${ }^{26} \mathrm{Al}$ and ${ }^{41} \mathrm{Ca}\left(t_{1 / 2} \sim 0.1 \mathrm{Myr}\right)$ in CAIs (Sahijpal et al. 1998), (2) discovery of ${ }^{60} \mathrm{Fe}\left(t_{1 / 2} \sim 1.5 \mathrm{Myr}\right)$, which can be produced only by stellar nucleosynthesis, in a chondrule (Huss \& Tachibana 2004), and (3) lack of correlation between ${ }^{26} \mathrm{Al}$ and ${ }^{10} \mathrm{Be}$ in CAIs (Marhas et al. 2002).

Here we report oxygen and ${ }^{26} \mathrm{Al}-{ }^{26} \mathrm{Mg}$ isotopic systematics of refractory inclusions and chondrules in CR chondrites that constrain the temporal history of ${ }^{16} \mathrm{O}$-rich and ${ }^{16} \mathrm{O}$-poor gaseous reservoirs in the inner solar nebula. We also describe an astrophysical mechanism by which the ${ }^{16} \mathrm{O}$-poor gas can be delivered to the chondrule-forming region on the appropriate timescale and in the appropriate abundance. Our observations indicate that the ${ }^{16} \mathrm{O}$-poor gaseous reservoir may have appeared rather early and persisted for at least $2 \mathrm{Myr}$, consistent with models by Lyons \& Young (2004), Yurimoto \& Kuramoto (2004), and Cuzzi \& Zahnle (2004). However, more studies need to be done to refine the timing of this transition.

\section{SAMPLES AND ANALYTICAL METHODS}

This section describes our methodology in some detail; readers uninterested in the specifics of the measurements may skip to $\S 5$. Twenty-nine polished sections of $16 \mathrm{CR}$ chondrites (Acfer 087, Acfer 139, EET 87730, EET 87747, EET 87770, EET 92041, EET 92042, EET 92147, El Djouf 001, GRA 95229, MAC 87320, MET 00426, PCA 91082, Renazzo, Temple Bar, and QUE 99177) were studied using optical microscopy, backscattered-electron (BSE) imaging, X-ray elemental mapping, and electron-probe microanalysis. X-ray elemental maps with a resolution of $2-5 \mu \mathrm{m}$ pixel $^{-1}$ were acquired with a five-spectrometer Cameca SX50 microprobe operating at $15 \mathrm{kV}$ accelerating voltage, $50-100 \mathrm{nA}$ beam current and $\sim 1-2 \mu \mathrm{m}$ beam size. The $\mathrm{Mg}, \mathrm{Ca}$, and Al X-ray images were combined by using an RGB color scheme and ENVI (Environment for Visualizing Images) software to obtain false-color maps to identify all refractory inclusions and aluminum-rich chondrules suitable for oxygen and magnesium isotopic studies. BSE images were obtained with Zeiss DSM 962, JEOL JSM-5900LV, and LEO 1430VP scanning electron microscopes using a $15-20 \mathrm{kV}$ accelerating voltage and 1-2 nA beam current. Electron-probe microanalyses were performed with a Cameca SX50 electron microprobe using a $15 \mathrm{kV}$ accelerating voltage, $10-20 \mathrm{nA}$ beam current, beam size of $\sim 1-2 \mu \mathrm{m}$, and wavelength-dispersive X-ray spectroscopy. The mineralogy and petrology of CAIs, AOAs, and aluminum-rich chondrules in CR chondrites have been described in detail in two companion papers (Aléon et al. 2002; Krot \& Keil 2002) and are not discussed here.

Oxygen isotopic compositions in chondrules were measured in situ with a Cameca IMS 1270 ion microprobe operated in multicollection mode. ${ }^{16} \mathrm{O}$ and ${ }^{18} \mathrm{O}$ were measured using Faraday cups; ${ }^{17} \mathrm{O}$ was measured using the axial electron multiplier. $\mathrm{A} \mathrm{Cs}^{+}$primary beam of $10 \mathrm{nA}$ was used to produce ion-probe sputter pits approximately $25-30 \mu \mathrm{m}$ in diameter. With such conditions, the count rate was $\sim 2 \times 10^{6}$ counts $\mathrm{s}^{-1}$ for ${ }^{18} \mathrm{O}$. Corrections for instrumental mass fractionation (IMF), counting statistics, and uncertainty in standard compositions were applied. The IMF was corrected using terrestrial standards: olivine, clinopyroxene, orthopyroxene, mid-ocean ridge basalt (MORB) glass, adularia, spinel, and quartz. Under the analytical conditions employed, the total precision $(2 \%)$ of individual oxygen isotopic analyses is better than $1.5 \%$ for both $\delta^{18} \mathrm{O}$ and $\delta^{17} \mathrm{O}$. Oxygen isotopic compositions in CAIs and AOAs were measured in situ with the UCLA Cameca IMS 1270 using the operating conditions and procedures described in Aléon et al. (2002). Following oxygen isotopic measurements, each refractory inclusion and chondrule analyzed was reexamined in BSE and secondary-electron images using a JEOL 5900LV scanning electron microscope to verify the locations of the sputtered craters and mineralogy of the phases analyzed.

Magnesium-isotope compositions were measured in situ with PANURGE, a modified Cameca IMS $3 \mathrm{f}$ ion microprobe at Lawrence Livermore National Laboratory, using the operating conditions and procedures described in Hutcheon et al. (1987). The $\mathrm{Mg}$ isotope ratios were corrected for both instrumental and intrinsic fractionation assuming the standard ratios of ${ }^{25} \mathrm{Mg} /{ }^{24} \mathrm{Mg}=0.12663$ and ${ }^{26} \mathrm{Mg} /{ }^{24} \mathrm{Mg}=0.13932$ (Catanzaro et al. 1966). The corrected ratios $\left({ }^{26} \mathrm{Mg} /{ }^{24} \mathrm{Mg}\right)_{\mathrm{C}}$ were used to calculate $\delta^{26} \mathrm{Mg}=\left[\left({ }^{26} \mathrm{Mg} /{ }^{24} \mathrm{Mg}\right)_{\mathrm{C}} / 0.13932-1\right] \times 10^{3}$.

\section{RESULTS}

Oxygen isotopic compositions of the CR chondrules plot along the line of slope $\sim 1$ (Figs. $1 a, 1 b$ ). The aluminum-rich chondrules with relict CAIs (Figs. $2 a, 2 b$ ) have heterogeneous oxygen isotopic compositions, with the relict spinel and anorthite being ${ }^{16} \mathrm{O}$-enriched $\left(\Delta^{17} \mathrm{O}=-15 \%\right.$ to $-10 \%$ o compared with the chondrule phenocrysts and mesostasis $\left(\Delta^{17} \mathrm{O}=-7 \%\right.$ to $-5 \%$ ). The aluminum-rich chondrules without relict CAIs (Fig. 2c), as well as magnesian porphyritic olivine and porphyritic olivine-pyroxene (type I) chondrules, are isotopically uniform (within $\pm 2 \%$ in $\Delta^{17} \mathrm{O}$ ) and have similarly ${ }^{16} \mathrm{O}$-poor compositions $\left(\Delta^{17} \mathrm{O}\right.$ ranges from $-5 \%$ to $\left.-1 \%\right)$. Because the aluminum-rich chondrules and type I chondrules formed by melting of various proportions of aluminum-rich and ferromagnesian precursors (Krot \& Keil 2002; Krot et al. 2001, 2002a, 2004a) that had different oxygen isotopic compositions (Krot et al. 2004b), we infer that both chondrule types experienced melting and oxygen isotopic exchange in the same ${ }^{16} \mathrm{O}$-poor gaseous reservoir. 

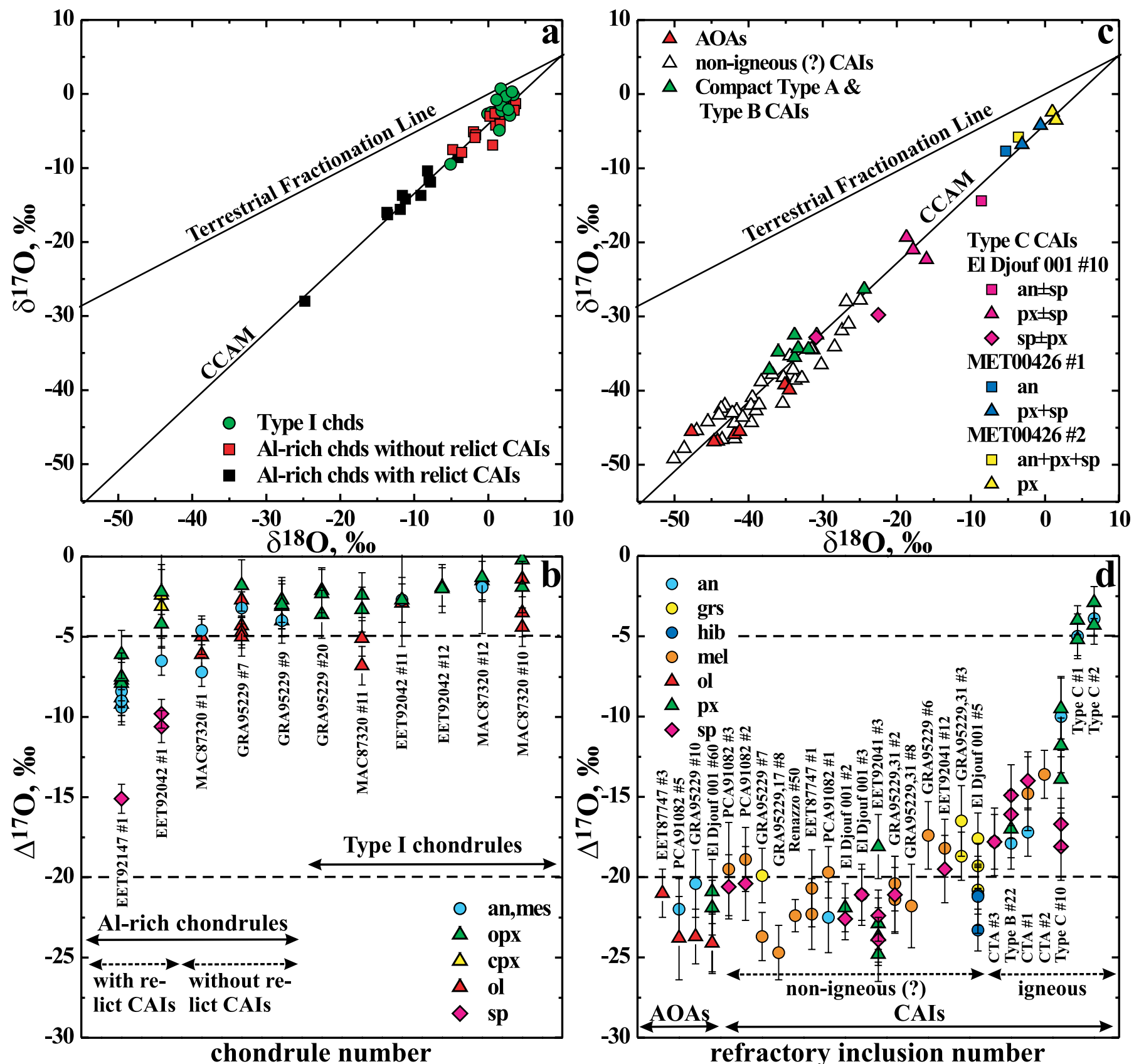

FIG. 1.-Oxygen isotopic compositions of chondrules and refractory inclusions in CR carbonaceous chondrites. Oxygen isotopic compositions of the refractory inclusions and chondrules in $(a)$ and $(c)$ are plotted as $\delta^{17} \mathrm{O}$ vs. $\delta^{18} \mathrm{O}\left(\delta^{\{17,18\}} \mathrm{O}=\left[\left({ }^{17,18\}} \mathrm{O} /{ }^{16} \mathrm{O}\right)_{\text {sample }} /\left({ }^{\{17,18\}} \mathrm{O} /{ }^{16} \mathrm{O}\right)_{\text {SMOW }}-1\right] \times 10^{3}\right.$; SMOW is Standard Mean Ocean Water; $2 \sigma$ error bars, not shown for clarity, are $\sim 2 \%$ and $\sim 1 \%$ for $\delta^{17} \mathrm{O}$ and $\delta^{18} \mathrm{O}$, respectively); the data follow the mass-independent fractionation (carbonaceous chondrite anhydrous mineral, CCAM) line. In $(b)$ and $(d)$, the same data are plotted in the form of deviation from the terrestrial fractionation line, as $\Delta^{17} \mathrm{O}$ $\left(\Delta^{17} \mathrm{O}=\delta^{17} \mathrm{O}-0.52 \delta^{18} \mathrm{O}\right)$; error bars are $2 \sigma$. Each column represents data for a single chondrule or refractory inclusion (chondrule and refractory inclusion numbers are indicated) and shows variations in oxygen isotopic composition within an individual object. Aluminum-rich chondrules and magnesium-rich (type I) chondrules are ${ }^{16} \mathrm{O}$-depleted relative to amoeboid olivine aggregates (AOAs) and most Ca-Al-rich inclusions (CAIs). Aluminum-rich chondrules with relict CAIs (see Figs. $2 a, 2 b$ ) are ${ }^{16} \mathrm{O}$-enriched compared with those without relict CAIs (see Fig. $2 c$ ) and type I chondrules. Clearly igneous (compact type A [CTA], type B, and type C) CAIs are ${ }^{16} \mathrm{O}$-depleted compared with AOAs and non-igneous (?) CAIs. Three type C CAIs (shown in Figs. $3 d-3 f$ ) are ${ }^{16} \mathrm{O}-\mathrm{depleted} \mathrm{to} \mathrm{a} \mathrm{level} \mathrm{observed} \mathrm{in} \mathrm{the} \mathrm{CR} \mathrm{chondrules.}$ Aluminum-rich chondrules with relict CAIs show oxygen isotopic heterogeneity, with spinel being ${ }^{16} \mathrm{O}$-enriched relative to anorthite and chondrule phenocrysts. Aluminum-rich chondrules without relict CAIs and type I chondrules are isotopically uniform. The only exception is a type I chondrule, No. 11 from MAC 87320 , that contains an ${ }^{16} \mathrm{O}$-enriched relict olivine grain. Abbreviations in the key refer to (an) anorthite or anorthitic plagioclase; (cpx) high-Ca pyroxene; (grs) grossite; (hib) hibonite; (mel) melilite; (mes) glassy or microcrystalline mesostasis; (ol) forsteritic olivine; (opx) low-Ca pyroxene; (px) Al-Ti pyroxene; and (sp) spinel. The igneous CAIs are as follows: CTA No. 1 = GRA 95229 No. 1; CTA No. $2=$ GRA 95229 No. 2 ; CTA No. $3=$ GRA 95229 No. 3 ; type B No. $22=$ GRA 95229 No. 22 ; type C No. 1 = MET 00426 No. 1; type C No. 2 = MET 00426 No. 2; type C No. 10 = El Djouf 001 No. 10. 

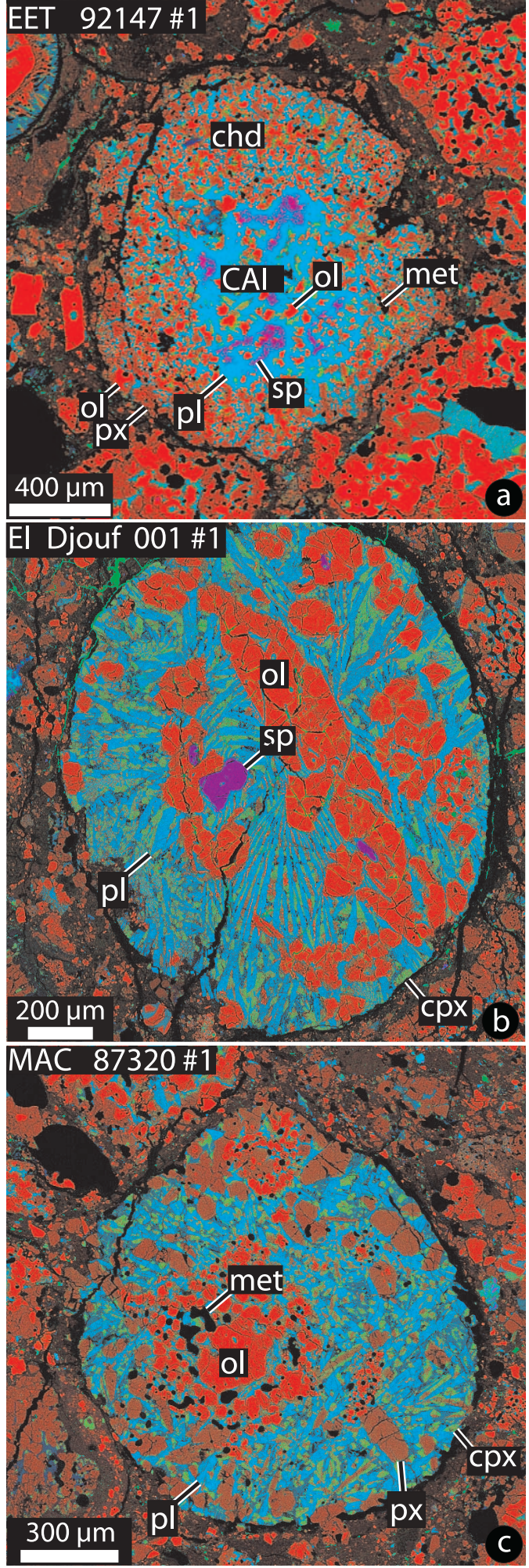

FIG. 2.-Combined elemental maps in $\mathrm{Mg}$ (red), $\mathrm{Ca}$ (green), and $\mathrm{Al} \mathrm{K} \alpha$ (blue) X-rays of the aluminum-rich chondrules $(a)$ No. 1 from EET 92147, (b) No. 1 from El Djouf 001, and (c) No. 1 from MAC 87320. The chondrules consist of forsteritic olivine (ol), low-Ca pyroxene ( $\mathrm{px}$ ), high-Ca pyroxene (cpx), anorthitic plagioclase (pl), Fe-Ni metal (met), and fine-grained mesostasis composed of silica, high-Ca pyroxene, and anorthitic plagioclase. Chondrule EET 92147 No. 1 contains an incompletely melted, relict CAI composed largely of spinel (sp), forsteritic olivine, and anorthitic plagioclase. Chondrule El Djouf 001 No. 1 experienced more complete melting and contains only rare relict spinel grains; no relict grains are observed in the most extensively melted chondrule, MAC 87320 No. 1. Oxygen isotopic compositions of EET 92147 No. 1 and MAC 87320 No. 1 are shown in Fig. $1 b$.
AOAs and most CAIs in CR chondrites are ${ }^{16} \mathrm{O}$-rich $\left(\Delta^{17} \mathrm{O} \sim\right.$ $-20 \%$ ), while CAIs that are clearly igneous in origin ${ }^{10}$ (compact type A, type B, and type C; Fig. 3) are ${ }^{16} \mathrm{O}$-depleted relative to AOAs to various degrees (Figs. $1 c, 1 d$ ). Three compact type A CAIs and a type B CAI (Figs. $3 a-3 c$ ) are only slightly less ${ }^{16} \mathrm{O}$-rich $\left(\Delta^{17} \mathrm{O} \sim-18 \%\right.$ to $-15 \%$ ) than AOAs and have the canonical $\left({ }^{26} \mathrm{Al} /{ }^{27} \mathrm{Al}\right)_{0}$ ratio of $\sim 5 \times 10^{-5}$ (Figs. $\left.4 a, 4 b\right)$. We infer that these CAIs experienced early melting in a slightly ${ }^{16} \mathrm{O}$-depleted gaseous reservoir.

All three type C CAIs studied-El Djouf 001 No. 10, MET 00426 No. 1, and MET 00426 No. 2 (Figs. $3 d-3 f$ ) - are depleted in ${ }^{16} \mathrm{O}$ to levels comparable to those observed in the CR chondrules (Fig. 1). We infer that these CAIs experienced melting and oxygen isotopic exchange in the presence of ${ }^{16} \mathrm{O}$-poor gas. El Djouf 001 No. 10 shows striking oxygen isotopic heterogeneity, with spinel being ${ }^{16} \mathrm{O}$-enriched relative to anorthite and Al-Ti pyroxene, indicating incomplete melting and oxygen isotopic exchange. MET 00426 No. 1 and MET 00426 No. 2 are isotopically uniform. El Djouf 001 No. 10 and MET 00426 No. 2 have low $\left({ }^{26} \mathrm{Al} /{ }^{27} \mathrm{Al}\right)_{0}$ ratios of $(0.8 \pm 1.8) \times 10^{-6}$ and less than $6.3 \times 10^{-6}$, respectively (Figs. $4 d, 4 e$ ), similar to those in the aluminum-rich chondrules from $\mathrm{CR}$ chondrites (Fig. 4f; Marhas et al. 2000), suggesting a late-stage melting, more than $2 \mathrm{Myr}$ after formation of CAIs with the canonical $\left({ }^{26} \mathrm{Al} /{ }^{27} \mathrm{Al}\right)_{0}$ ratio, possibly contemporaneously with the $\mathrm{CR}$ chondrules (Amelin et al. 2002). MET 00426 No. 1 has a high $\left({ }^{26} \mathrm{Al} /{ }^{27} \mathrm{Al}\right)_{0}$ ratio of $(4.0 \pm 1.8) \times 10^{-5}$ (Fig. $4 c$ ), suggesting melting and oxygen isotopic exchange in an ${ }^{16} \mathrm{O}$-poor nebular region within $0.8 \mathrm{Myr}$ of CAIs with a canonical $\left({ }^{26} \mathrm{Al} /{ }^{27} \mathrm{Al}\right)_{0}$ ratio forming in an ${ }^{16} \mathrm{O}$-rich nebular region. Below, we discuss possible mechanisms and timescales for the early variation of oxygen isotopes in the inner solar nebula - the region where CAIs and chondrules most likely formed (Cassen 2001; Desch \& Connolly 2002; Cuzzi et al. 2003).

\section{6. ${ }^{16} \mathrm{O}$-RICH AND ${ }^{16} \mathrm{O}$-POOR GASEOUS REGIONS IN THE SOLAR NEBULA}

Our data for chondrules and refractory inclusions in CR chondrites clearly indicate that the oldest, and highest-temperature, condensates (CAIs and AOAs) are the richest in ${ }^{16} \mathrm{O}$, and that nebular condensates interacted with a successively ${ }^{16} \mathrm{O}$-poorer gas as time progressed. Our observations have begun to set timescales for this transition. Below, we describe the process that we suggest was responsible for this transition, comparing its predicted timescales with our observations, and then make some comments on the initial ${ }^{16} \mathrm{O}$-rich state.

\subsection{Late-Stage, ${ }^{16} \mathrm{O}$-poor Environment}

According to our model and those of Clayton (2002), Lyons \& Young (2004), and Yurimoto \& Kuramoto (2004), initially the nebular gas was ${ }^{16} \mathrm{O}$-rich. During this time ${ }^{16} \mathrm{O}$-rich AOAs and primitive CAIs with canonical $\left({ }^{26} \mathrm{Al} /{ }^{27} \mathrm{Al}\right)_{0}$ ratio formed. The formation at a later time of ${ }^{16} \mathrm{O}$-depleted chondrules and igneous CAIs requires both the formation and the subsequent transfer of an ${ }^{16} \mathrm{O}$-depleted carrier (presumably $\mathrm{H}_{2} \mathrm{O}$ ) to the inner solar nebula separately from the complementary ${ }^{16} \mathrm{O}$-enriched carrier (presumably $\mathrm{CO}$ or primordial silicates) on a timescale that matches our observations. In the protoplanetary disk, outside $5 \mathrm{AU}$ from the Sun (the inferred location of the

10 There are three major mineralogical types of igneous CAIs: (1) compact type A, composed of melilite with very little pyroxene; (2) type B, made of melilite, spinel, pyroxene, and anorthite; and (3) anorthite-rich, type C CAIs (see MacPherson et al. 1988 for a review). 


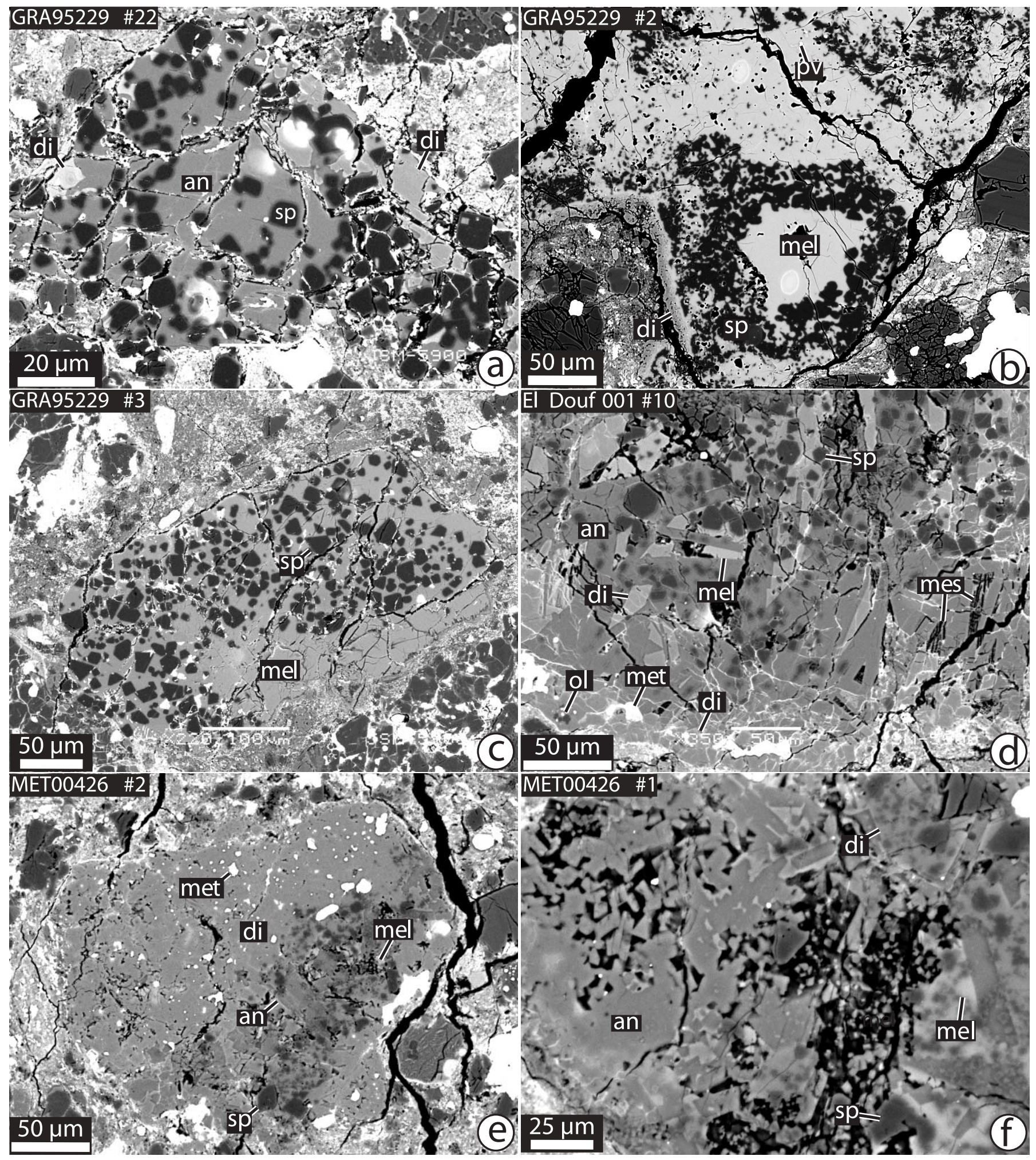

FIG. 3. - Backscattered-electron images of the igneous, $(a-c){ }^{16} \mathrm{O}$-rich and $(d-f){ }^{16} \mathrm{O}$-poor CAIs from the CR carbonaceous chondrites. $(a)$ Type B CAI GRA 95229 No. 22; (b) CTA CAI GRA 95229 No. 2; (c) CTA CAI GRA 95229 No. 3; $(d-f)$ type C CAIs El Djouf 001 No. 10, MET 00426 No. 2 , and MET 00426 No. 1 , respectively. Labels denote (an) anorthite; (di) Al-Ti diopside; (mel) melilite; (mes) mesostasis; (met) Fe-Ni metal; (ol) forsteritic olivine; (pv) perovskite; and (sp) spinel. Oxygen isotopic compositions of these CAIs are shown in Fig. $1 d$. 

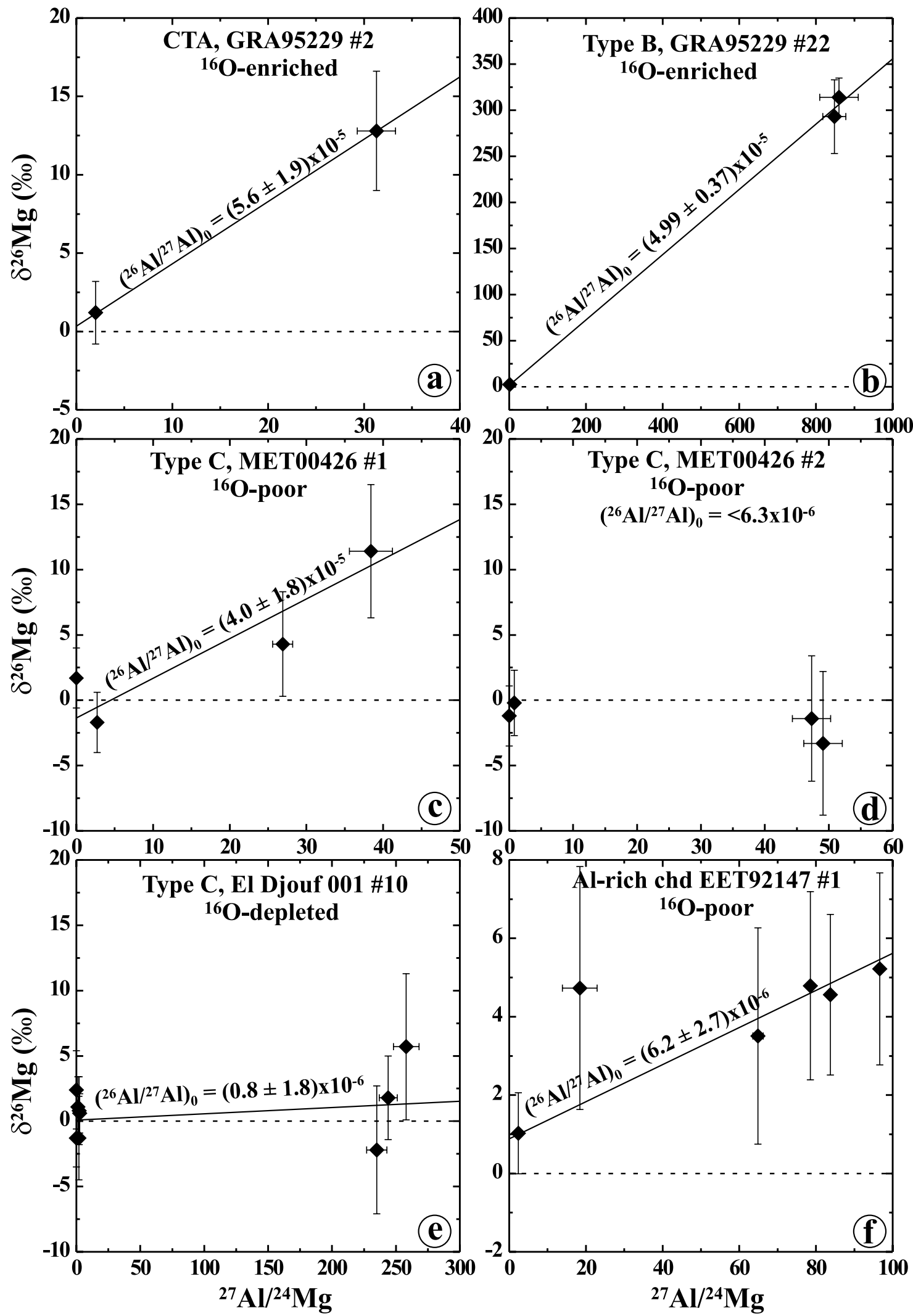

FIg. 4.-Aluminum-magnesium evolutionary diagrams of $(a)$ the ${ }^{16}$ O-enriched CTA CAI GRA 95229 No. 2, $(b)$ the ${ }^{16}$ O-enriched type B CAI GRA 95229 No. 22 , $(c-e)$ the ${ }^{16} \mathrm{O}$-depleted/-poor type C CAIs MET 00426 No. 1, MET 00426 No. 2, and El Djouf 001 No. 10, respectively, and $(f)$ the ${ }^{16} \mathrm{O}$-poor Al-rich chondrule with a relict CAI, EET $92147 \mathrm{No} .1$. The $\left({ }^{26} \mathrm{Al} /{ }^{27} \mathrm{Al}\right)_{0}$ ratios in the ${ }^{16} \mathrm{O}$-enriched CAIs are close to the canonical ratio of $5 \times 10^{-5}$, suggesting an early melting. The high $\left({ }^{26} \mathrm{Al} /{ }^{27} \mathrm{Al}\right)_{0}$ ratio in the ${ }^{16} \mathrm{O}$-poor type CAI MET $00426 \mathrm{No}$. 1 suggests that its melting and oxygen isotopic exchange occurred not more than $0.8 \mathrm{Myr}$ after formation of CAIs with the canonical $\left({ }^{26} \mathrm{Al} /{ }^{27} \mathrm{Al}\right)_{0}$ ratio. The $\left({ }^{26} \mathrm{Al} /{ }^{27} \mathrm{Al}\right)_{0}$ ratios in the ${ }^{16} \mathrm{O}$-poor CAIs El Djouf 001 No. 10 and MET00426 No. 2 and the Al-rich chondrule with relict $\mathrm{CAI}$ are low, suggesting they experienced melting and oxygen isotopic exchange more than $2 \mathrm{Myr}$ later. 
condensation-evaporation front of water, called the "snow line"), water ice enriched in ${ }^{17} \mathrm{O}$ and ${ }^{18} \mathrm{O}$, resulting from $\mathrm{CO}$ selfshielding in the molecular cloud or at high altitudes in the disk, aggregates into large particles that settle down to the disk midplane, causing $\mathrm{H}_{2} \mathrm{O} / \mathrm{CO}$ fractionation and enrichment of this region in heavy oxygen (Yurimoto \& Kuramoto 2004). If selfshielding only occurred in the protoplanetary disk, it would have taken approximately $1 \mathrm{Myr}$ to achieve the level of ${ }^{17} \mathrm{O}$ and ${ }^{18} \mathrm{O}$ enrichment in water ice observed in aqueously formed chondritic minerals (Lyons \& Young 2004). This transformation timescale greatly exceeds that for either vertical mixing or for particle growth and settling to the midplane (Cuzzi \& Weidenschilling 2005). If CO self-shielding took place in the parent molecular cloud and the solar nebula initially contained ${ }^{16} \mathrm{O}$-depleted $\mathrm{H}_{2} \mathrm{O}$ and ${ }^{16} \mathrm{O}$-enriched $\mathrm{CO}$, the transformation timescale could be significantly shorter (Yurimoto \& Kuramoto 2004). Here we note that vigorous transfer of this ${ }^{17} \mathrm{O}$ - and ${ }^{18} \mathrm{O}$-enriched, outer nebula water to the inner nebula (Yurimoto \& Kuramoto 2004; Lyons \& Young 2004) is a natural outcome of the evaporation-front process described in Cuzzi et al. (2003) and Cuzzi \& Zahnle (2004). We also note implications for astronomical observations.

In the past, it has often been asserted that meter-sized particles drift radially inward at rates that are so large that they are "lost into the Sun" on short timescales. However, drifting particles would evaporate before-sometimes long beforethey got that far; the full implications of this process have not previously been appreciated. A systematic study of "evaporation fronts" was first done by Cuzzi et al. (2003), in the context of CAI formation and evolution near the silicate evaporation front; a more recent study by Cuzzi \& Zahnle (2004) focused on the water evaporation front. In these papers, it was shown how a small meter-sized fraction of the total solids could drift so rapidly that it dominates the net inward mass flux of all other solids. It was suggested in Cuzzi et al. (2003) and Cuzzi \& Zahnle (2004), and discussed in more detail in Cuzzi \& Weidenschilling (2005), that growth to meter size is not difficult in either turbulent or nonturbulent nebulae, but that further growth can be frustrated by even a small amount of turbulence. Essentially, relative velocities between particles smaller than a meter are small enough that growth of crushable, but cohesive, particles by simple sticking is quite plausible. ${ }^{11}$ Thus, a distribution extending from micron-sized to meter-sized particles might form very quickly and persist for a long time. In such a distribution, which has equal mass per decade in radius, the mass fraction in metersized particles is of order 0.1. Weidenschilling $(1997,2000)$ finds such distributions quite generally at 1,30 , and 90 AU after different times; at $30 \mathrm{AU}$, this distribution arises before $10^{5} \mathrm{yr}$ have elapsed.

Water ice particles evaporate quickly, fairly close to the evaporation front (Cuzzi \& Zahnle 2004; Supulver \& Lin 2000). Cyr et al. (1998) modeled the evaporation of drifting water ice boulders, but the extensive radial drifts they present are not consistent with plausible nebula thermal structure, for reasons that remain unclear (Cuzzi \& Zahnle 2004). Once the water has evaporated just inside the evaporation front and become mingled with the nebular gas, it is trapped to the slow radial evolution of the nebula and leaves the region of the evaporation front (as vapor) much more slowly than it arrives from outside (as solids). The abundance of water in the vapor phase thus grows significantly until its loss by inward nebular advection, and

\footnotetext{
11 This conclusion is also reached by recalculating particle size limits following Weidenschilling (1988) under a lower nebular turbulent intensity than the $\alpha=10^{-2}$ assumed therein.
}

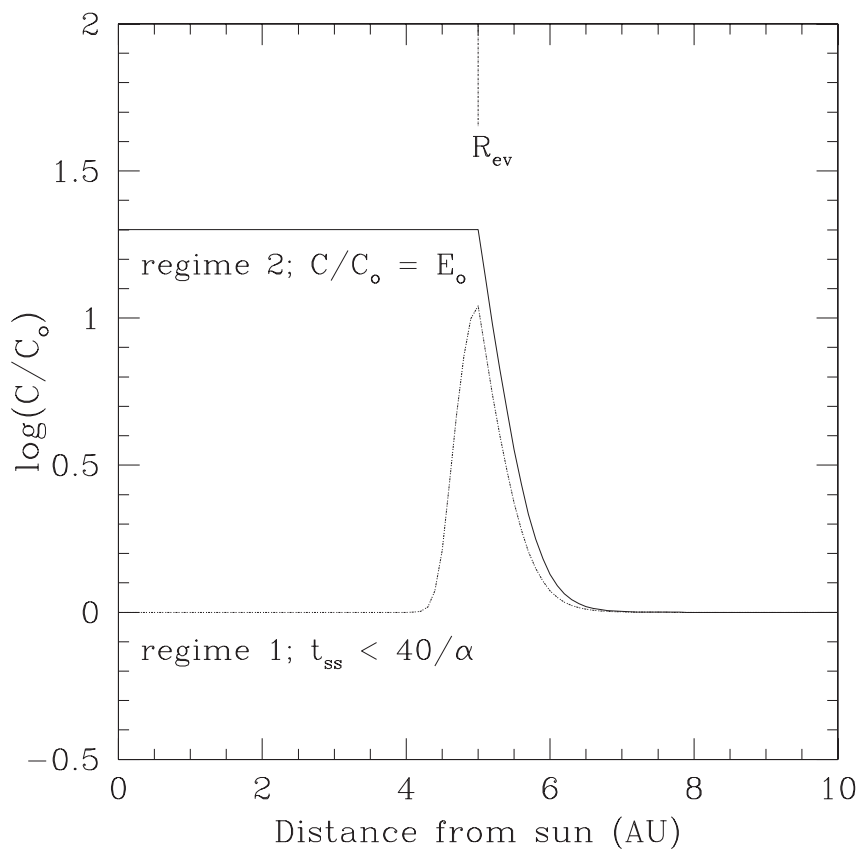

FIG. 5.-Schematic of the radial and temporal variation of enhancement $E_{0}=$ $C / C_{0}$ for water with an evaporation boundary at $R_{\mathrm{ev}}=5 \mathrm{AU}$. Regime 1 represents the transition situation, where the inner solar nebula retains $E_{0}=1$ for up to $t_{\mathrm{ss}}=$ $40 / \alpha$ orbit periods. Regime 2 is the steady state situation for times longer than $t_{\mathrm{ss}}$, where the inner solar nebula is enriched in water (as vapor) by a factor of 20 in this example. It takes between 0.5 and $5 \mathrm{Myr}$ (depending on nebular properties) for the enhancement water plume at $5 \mathrm{AU}$ to spread throughout the inner solar system into its steady state configuration. (After Cuzzi \& Zahnle 2004.)

diffusion down inward and outward concentration gradients can balance the large incoming flux in drifting meter-sized particles (see also the discussion in Yurimoto \& Kuramoto 2004).

The degree of enrichment $E_{0}=C / C_{0}$, where $C_{0}$ and $C$ are respectively the cosmic and the locally enhanced abundance of water relative to hydrogen, is determined by the nebular viscosity parameter $\alpha$ and the mass fraction $f_{L}$ of rapidly drifting particles: $E_{0} \approx 2 f_{L} / 3 \alpha$. Enhancements in $\mathrm{H}_{2} \mathrm{O}$ of $E_{0}=10-100$ are calculated under the assumptions that the nebula has $\alpha=10^{-2}$ to $10^{-3}$ (smaller values give larger enrichments) and that metersized particles constitute about $f_{L}=0.1$ of the local solid mass; this in turn relies on modeling of incremental growth with erosion and destruction, which indicates that particles can indeed grow to roughly meter size in times of 100-1000 yr even if the nebula is weakly turbulent (Weidenschilling 1997; Cuzzi et al. 2003; Cuzzi \& Weidenschilling 2005; Weidenschilling \& Cuzzi 2005). The specific value of $E_{0}$ and the specific ${ }^{16} \mathrm{O}$ depletion of the $\mathrm{H}_{2} \mathrm{O}$ are coupled and remain to be constrained. This can be done by measurements of oxygen isotopic composition of water in cometary ices, or by astronomical observations of the relative abundance of water in the vapor form at different locations in protoplanetary disks of different ages and accretion rates (thermal structures).

Analytical solutions of the equations governing this driftdiffusion situation show three different regimes (Cuzzi \& Zahnle 2004). At very small times, a plume of enhanced water appears just inside the evaporation front (Fig. 5; regime 1). It takes a certain amount of time for this plume to spread into the inner solar system. Spreading occurs as a result of both the steady, but slow, inward drift of the nebular gas and also diffusion down the inward concentration gradient of regime 1 . The timescales for these processes are comparable: $t_{\mathrm{ss}}=0.5-5 \mathrm{Myr}$, if nebular evolution is by turbulent viscosity (Cuzzi \& Zahnle 2004). After a time $t_{\mathrm{ss}}$, 
the solutions indicate a uniformly enhanced abundance everywhere inside the evaporation front (Fig. 5; regime 2). There may be a third regime, initially described by Stevenson \& Lunine (1988), in which an immobile sink or "cold finger" forms outside the evaporation front and depletes the inner nebula in volatiles (regime 3 of Cuzzi \& Zahnle 2004; not discussed here). These regimes might have other implications for meteoritics than discussed here (cf. Cuzzi \& Zahnle 2004).

Since chondrule formation involved melting of solids during multiple heating episodes (Desch \& Connolly 2002) and appears to have persisted for at least $2 \mathrm{Myr}$ after the formation of pristine CAIs (Russell et al. 1996; Kita et al. 2000; Marhas et al. 2000; Amelin et al. 2002, 2004), these models are consistent with most chondrules exchanging oxygen with an ${ }^{16} \mathrm{O}$-poor nebular gas in regime 2. Chondrules and fine-grained matrices are chemically complementary, suggesting that they formed in the same location (Kong 1999; Klerner \& Palme 2000; Bland et al. 2004). Because most of the fine-grained matrix materials are expected to be vaporized and recondensed during chondruleforming events (Desch \& Connolly 2002), they would also have exchanged their oxygen with an ${ }^{16} \mathrm{O}$-poor nebular gas. This suggestion is consistent with the relatively ${ }^{16} \mathrm{O}$-poor compositions of chondrules and matrix materials (this paper; also Clayton et al. 1977; Clayton 1993; Maruyama et al. 1999; Krot et al. 2004b; Jones et al. 2004; Nagashima et al. 2004).

\subsection{Locally Early- and Late-Stage, ${ }^{16} \mathrm{O}-$ rich Environment}

If the initial oxygen isotopic composition of dust and gas in the presolar molecular cloud was ${ }^{16} \mathrm{O}$-rich (Genesis results will hopefully clarify this issue), as suggested by Clayton (2002) and Yurimoto \& Kuramoto (2004), and if ${ }^{16} \mathrm{O}$-rich presolar dust was evaporated in more than its nominal cosmic abundance in the inner nebula, the ensuing gas would become ${ }^{16} \mathrm{O}$-rich regardless of the isotopic composition of the nebular gas (Cassen 2001; Scott \& Krot 2001; Kobayashi et al. 2003; Itoh \& Yurimoto 2003; Cuzzi et al. 2003). An enrichment of the nebular source region of CAIs and AOAs in ice-free silicates by a factor of 10 100 relative to the solar composition is also necessary to account for the observed range of $\mathrm{FeO}$ content in the ${ }^{16} \mathrm{O}$-rich olivine and low-Ca pyroxene condensates in AOAs (Nagashima et al. 2004; Krot et al. 2004d, 2005). In a process analogous to the water evaporation front discussed above, silicate material could have been comparably enhanced inside the silicate evaporation boundary $\left(\sim 1375 \mathrm{~K}\right.$ for forsterite at total pressure of $10^{-4}$ bars; Cuzzi et al. 2003). Models of evolving nebulae by, for instance, Bell et al. (1997), Stepiński (1998), and Cassen (2001), and widely scattered observational data (Calvet et al. 2000) tend to show mass accretion rates in the range of $10^{-6}$ to $10^{-7} M_{\odot} \mathrm{yr}^{-1}$ for, typically, $10^{4}-10^{5}$ yr. For these accretion rates, midplane temperatures would be much higher than the photospheric temperatures directly observed and could exceed the evaporation temperature of forsterite in the terrestrial planet region (Woolum \& Cassen (1999).

However, such local ${ }^{16} \mathrm{O}$-rich environments could not have formed after the inner nebula became too cool to evaporate silicates. In addition, ${ }^{16} \mathrm{O}$-rich (i.e., primordial) silicates could be difficult to preserve in the later epoch of the solar nebula because of their cumulative thermal processing under conditions known to be increasingly ${ }^{16} \mathrm{O}$-poor. Moreover, the relatively high abundances of moderately volatile elements ( $\mathrm{Mn}, \mathrm{Cr}, \mathrm{Na})$ in typical chondrules suggest that chondrules formed at lower ambient temperatures than CAIs and AOAs, that is, below the condensation temperature of forsterite (Krot et al. 2002c). Thus it is very unlikely that chondrules could have formed in a locally generated, late-stage, ${ }^{16} \mathrm{O}$-rich environment. Indeed, uniformly ${ }^{16} \mathrm{O}$-rich chon- drules are extremely rare; ${ }^{12}$ only one uniformly ${ }^{16} \mathrm{O}$-rich chondrule has been reported so far (Kobayashi et al. 2003).

\section{SUMMARY}

In this paper we have shown that refractory inclusions in primitive CR chondrites, which solidified (either as condensates or from melts) early, and generally at high temperatures, equilibrated with a gas that was richer in ${ }^{16} \mathrm{O}$ than later forming solid particles. We have suggested a mechanism by which ${ }^{16} \mathrm{O}-$ poor water, accreted as solids in the outer nebula from UV-photodissociated gas, was delivered to the inner nebula in significant amounts, and on fairly short timescales $(0.5-5 \mathrm{Myr})$. We found one igneous CAI that shows an ${ }^{26} \mathrm{Al}-{ }^{26} \mathrm{Mg}$ relative age of $\leq 0.8 \mathrm{Myr}$ after pristine CAIs with the canonical $\left({ }^{26} \mathrm{Al} /{ }^{27} \mathrm{Al}\right)_{0}$ ratio and still appears to have formed in an ${ }^{16} \mathrm{O}-$ poor environment. The similarly ${ }^{16} \mathrm{O}$-poor compositions of chondrules in CR chondrites suggest that this state persisted at least until the CR chondrules formed, that is, $\sim 1-2$ Myr later. Additional observations of this type will refine the timescale on which the transition between the ${ }^{16} \mathrm{O}$-rich and ${ }^{16} \mathrm{O}$-poor environments occurred.

Astronomical observations also have the potential to address these questions in several ways. The midplane temperatures in accreting disks are of great importance; thus, it is critical to distinguish between photospheric temperatures and midplane temperatures. Woolum \& Cassen (1999) have taken some first steps in this direction. Najita et al. (2003) have shown that actively accreting protoplanetary disks appear to have abundant gas-phase $\mathrm{CO}$ emission that extends well out into the terrestrial planet region; Carr et al. (2004) have found that, in some cases, disks or disk regions showing abundant $\mathrm{CO}$ emission show little water emission. These effects might be explained by differences in the excitation processes from place to place or time to time (Najita et al. 2003), but perhaps future work can begin to separate out excitation effects from abundance variations and provide evidence for or against zones of differentially enhanced (or depleted) water or $\mathrm{CO}$, or other molecules, in the vapor phase at different locations in protoplanetary disks of different ages.

Finally, we note that if chondrule formation initiated planetesimal accretion in the inner solar system (Scott 2002), the inner solar system planetesimals and planets should be ${ }^{16} \mathrm{O}$-poor, like chondrules; this is consistent with the existing data on Earth and meteorites from asteroids and Mars (e.g., Clayton 1993; McKeegan \& Leshin 2001). On the surface this seems a rather unremarkable conclusion, but it might serve to rule out formation of the planets from earlier-formed planetesimals that have only a thin surface veneer of chondritic material.

This work was supported by NASA grants NAG 5-10610 (A. N. K., PI), NAG 5-11591 (K. Keil, PI), UPN 344-37-22-03 (J. N. C., PI), W-19894 (I. D. H., PI), and NAG 5-4704 (K. D. M., PI) and by Monkasho grants (H. Y., PI). This work was performed under the auspices of the US Department of Energy by the University of California, Lawrence Livermore National Laboratory, under contract W-7405-Eng-48. This is Hawai' $i$ Institute of Geophysics and Planetology publication No. 1373 and School of Ocean and Earth Science and Technology publication No. 6550.

12 Jones et al. (2004) described two type I chondrules in a CV chondrite with olivine grains displaying a wide range of oxygen isotopic composition $\left(\Delta^{17} \mathrm{O}\right.$ from 0 up to $-25 \%$ ). The chondrules, however, have ${ }^{16} \mathrm{O}$-poor bulk compositions $\left(\Delta^{17} \mathrm{O} \sim-5 \%\right.$ ), suggesting that they formed by melting of ${ }^{16} \mathrm{O}$-rich precursors in an ${ }^{16} \mathrm{O}$-poor gaseous reservoir and experienced incomplete oxygen isotopic exchange. 
Aléon, J., Krot, A. N., \& McKeegan, K. D. 2002, Meteoritics Planet. Sci., 37, 1729

Aléon, J., Krot, A. N., McKeegan, K. D., MacPherson, G., \& Ulyanov, A. 2004, Meteoritics Planet. Sci., submitted

Amelin, Yu., Krot, A., \& Twelker, E. 2004, Geochim. Cosmochim. Acta, 68, A759

Amelin, Yu., Krot, A. N., Hutcheon, I. D., \& Ulyanov, A. A. 2002, Science, 297, 1678

Bizzarro, M., Baker, J., \& Haack, H. 2004, Nature, 431, 275

Bell, K. R., Cassen, P. M., Klahr, H. H., \& Henning, T. 1997, ApJ, 486, 372

Bland, P. A., Alard, O., Gounelle, M., Benedix, G. K., Kearsley, A. T., \& Rogers, N. W. 2004, in Lunar and Planetary Science XXXV (Houston: Lunar Planet. Inst.), No. 1737

Brigham, C. A., Hutcheon, I. D., Papanastassiou, D. A., \& Wasserburg, G. J. 1988, in Lunar and Planetary Science XIX (Houston: Lunar Planet. Inst.), 132

Calvet, N., Hartmann, L., \& Strom, S. E. 2000, in Protostars and Planets IV, ed. V. Mannings, A. P. Boss, \& S. S. Russell (Tucson: Univ. Arizona Press), 377

Carr, J. S., Tokunaga, A. T., \& Najita, J. 2004, ApJ, 603, 213

Cassen, P. 2001, Meteoritics Planet. Sci., 36, 671

Catanzaro, E., Murphy, T., Garner, E., \& Shields, W. 1966, J. Res. Natl. Bur. Stand., 70A, 453

Chaussidon, M., Robert, F., McKeegan, K. D. 2002, in Lunar and Planetary Science XXXIII (Houston: Lunar Planet. Inst.), No. 1563 2004, in Lunar and Planetary Science XXXV (Houston: Lunar Planet. Inst.), No. 1568

Choi, B.-G., McKeegan, K. D., Krot, A. N., \& Wasson, J. T. 1998, Nature, 392, 577

Clayton, R. N. 1993, Annu. Rev. Earth Planet. Sci., 21, 115 2002, Nature, 415, 860

Clayton, R. N., Onuma, N., Grossman, L., \& Mayeda, T. K. 1977, Earth Planet. Sci. Lett., 34, 209

Cuzzi, J., \& Weidenschilling, S. J. 2005, in Meteorites and the Early Solar System II, ed. D. Lauretta, L. A. Leshin, \& H. Y. McSween, Jr. (Tucson: Univ. Arizona Press), in press

Cuzzi, J. N., Davis, S. S., \& Dobrovolskis, A. R. 2003, Icarus, 166, 385

Cuzzi, J. N., \& Zahnle, K. J. 2004, ApJ, 614, 490

Cyr, K. E., Sears, W. D., \& Lunine, J. I. 1998, Icarus, 135, 537

Desch, S. J., \& Connolly, H. C., Jr. 2002, Meteoritics Planet. Sci., 37, 183

Fahey, A. J., Goswami, J. N., McKeegan, K. D., \& Zinner, E. K. 1987, ApJ, 323, L91

Galy, A., Hutcheon, I. D., \& Grossman, L. 2004, in Lunar and Planetary Science XXXV (Houston: Lunar Planet. Inst.), No. 1790

Goswami, J. N., McKeegan, K. D., Marhas, K. K., Sinha, N., \& Davis, A. M. 2001, in Lunar and Planetary Science XXXII (Houston: Lunar Planet. Inst.), No. 1576

Gounelle, M., Shu, F. H., Shang, H., Glassgold, A. E., Rehm, K. E., \& Lee, T. 2001, ApJ, 548, 1051

Greshake, A. 1997, Geochim. Cosmochim. Acta, 61, 437

Huss, G. R., \& Tachibana, S. 2004, in Lunar and Planetary Science XXXV (Houston: Lunar Planet. Inst.), No. 1811

Hutcheon, I. D., Armstrong, J. T., \& Wasserburg, G. J. 1987, Geochim. Cosmochim. Acta, 51, 3175

Ireland, T. R. 1990, Geochim. Cosmochim. Acta, 54, 3219

Itoh, S., Rubin, A. E., Kojima, H., Wasson, J. T., \& Yurimoto, H. 2002, in Lunar and Planetary Science XXXV (Houston: Lunar Planet. Inst.), No. 1490

Itoh, S., \& Yurimoto, H. 2003, Nature, 423, 728

Jones, R. H., Leshin, L. A., Guan, Y., Sharp, Z. D., Durakiewicz, T., \& Schilk, A. J. 2004, Geochim. Cosmochim. Acta, 68, 3423

Kita, N. T., Nagahara, H., Togashi, S., \& Morishita, Y. 2000, Geochim. Cosmochim. Acta, 64, 3913

Kitamura, Y., \& Shimizu, M. 1983, Moon Planets, 29, 199

Klerner, S., \& Palme, H. 2000, Meteoritics Planet. Sci., 35, A89

Kobayashi, S., Imai, H., \& Yurimoto, H. 2003, Geochem. J., 37, 663

Kong, P. 1999, Geochim. Cosmochim. Acta, 63, 3673

Krot, A. N., Fagan, T. J., Keil, K., McKeegan, K. D., Sahijpal, S., Hutcheon, I. D., Petaev, M. I., \& Yurimoto, H. 2004a, Geochim. Cosmochim. Acta, 68, 2167

Krot, A. N., Fagan, T. J., Yurimoto, H., \& Petaev, M. I. 2005, Geochim. Cosmochim. Acta, in press

Krot, A. N., Fegley, B., Jr., Lodders, K., \& Palme, H. 2000, in Protostars and Planets IV, ed. V. Mannings, A. P. Boss, \& S. S. Russell (Tucson: Univ. Arizona Press), 1019

Krot, A. N., Hutcheon, I. D., \& Huss, G. R. 2001, Meteoritics Planet. Sci., 36, A105

Krot, A. N., Hutcheon, I. D., \& Keil, K. 2002a, Meteoritics Planet. Sci., 37, 155

Krot, A. N., \& Keil, K. 2002, Meteoritics Planet. Sci., 37, 91
Krot, A. N., Libourel, G., \& Chaussidon, M. 2004b, in Lunar and Planetary Science XXXV (Houston: Lunar Planet. Inst.), No. 1389

Krot, A. N., McKeegan, K. D., Leshin, L. A., MacPherson, G. J., \& Scott, E. R. D. 2002b, Science, 295, 1051

Krot, A. N., Meibom, A., Weisberg, M. K., \& Keil, K. 2002c, Meteoritics Planet. Sci., 37, 1451

Krot, A. N., Petaev, M. I., Scott, E. R. D., Choi, B.-G., Zolensky, M. E., \& Keil, K. 1998, Meteoritics Planet. Sci., 33, 1065

Krot, A. N., Yurimoto, H., Hutcheon, I. D., \& Scott, E. R. D. 2004c, Meteoritics Planet. Sci., 39, A56

Krot, A., et al. 2004d, Chem. Erde, 64, 185

Lee, T., \& Shen, J. J. 2001, Meteoritics Planet. Sci., 36, A111

Lyons, J. E., \& Young, E. D. 2004, in Lunar and Planetary Science XXXV (Houston: Lunar Planet. Inst.), No. 1970

MacPherson, G. J. 2003, in Treatise on Geochemistry, Vol. 1, Meteorites, Comets, and Planets, ed. A. M. Davis (Oxford: Elsevier), 201

MacPherson, G. J., Davis, A. M., \& Zinner, E. K. 1995, Meteoritics, 30, 365

MacPherson, G. J., Wark, D. A., \& Armstrong, J. T. 1988, in Meteorites and the Early Solar System, ed. J. F. Kerridge \& M. S. Matthews (Tucson: Univ. Arizona Press), 746

Marhas, K. K., Goswami, J. N., \& Davis, A. M. 2002, Science, 298, 2182

Marhas, K. K., Hutcheon, I. D., Krot, A. N., \& Goswami, J. N. 2000, Meteoritics Planet. Sci., 35, A102

Marhas, K. K., Krot, A. N., \& Goswami, J. N. 2001, Meteoritics Planet. Sci., $36, \mathrm{~A} 121$

Maruyama, S., Yurimoto, H., \& Sueno, S. 1999, Earth Planet. Sci. Lett., 169, 165

McKeegan, K. D., Chaussidon, M., \& Robert, F. 2000, Science, 289, 1334

McKeegan, K. D., Krot, A. N., Taylor, D., Sahijpal, S., \& Ulyanov, A. A. 2004, Meteoritics Planet. Sci., 39, A66

McKeegan, K. D., \& Leshin, L. A. 2001, Rev. Mineral. Geochem., 43, 279

Nagashima, K., Krot, A. N., \& Yurimoto, H. 2004, Nature, 428, 921

Najita, J., Carr, J. S., \& Mathieu, R. D. 2003, ApJ, 589, 931

Nittler, L. R., Alexander, C. M. O'D., Gao, X., Walker, R. M., \& Zinner, E. 1997, ApJ, 483, 475

Nittler, L. R., Alexander, C. M. O’D., Wang, J., \& Gao, X. 1998, Nature, 393, 222

Russell, S., Hartmann, L., Cuzzi, J., Krot, A. N., Gounelle, M., \& Weidenschilling, S. 2005, in Meteorites and the Early Solar System II, ed. D. Lauretta, L. A. Leshin, \& H. Y. McSween, Jr. (Tucson: Univ. Arizona Press), in press

Russell, S. S., Srinivasan, G., Huss, G. R., Wasserburg, G. J., \& MacPherson, G. J. 1996, Science, 273, 757

Sahijpal, S., Goswami, J. N., Davis, A. M., Grossman, L., \& Lewis, R. S. 1998, Nature, 391, 559

Scott, E. R. D. 2002, in Asteroids III, ed. W. F. Bottke, A. Cellino, P. Paolicchoi, \& R. P. Binzel (Tucson: Univ. Arizona Press), 697

Scott, E. R. D., \& Krot, A. N. 2001, Meteoritics Planet. Sci., 36, 1307

. 2003, in Treatise on Geochemistry, Vol. 1, Meteorites, Comets, and Planets, ed. A. M. Davis (Oxford: Elsevier), 143

Shu, F. H., Shang, H., \& Lee, T. 1996, Science, 271, 1545

Stepiński, T. F. 1998, Icarus, 132, 100

Stevenson, D. J., \& Lunine, J. I. 1988, Icarus, 75, 146

Supulver, K. D., \& Lin, D. N. C. 2000, Icarus, 146, 525

Thiemens, M. H. 1996, in Chondrules and the Protoplanetary Disk, ed. R. H. Hewins, R. H. Jones, \& E. R. D. Scott (Cambridge: Cambridge Univ. Press), 107

Thiemens, M. H., \& Heidenreich, J. E., III. 1983, Science, 219, 1073

Wasson, J. T., Yurimoto, H., \& Russell, S. S. 2001, Geochim. Cosmochim. Acta, 65,4539

Weidenschilling, S. J. 1988, Meteorites and the Early Solar System, ed. J. F. Kerridge \& M. S. Matthews (Tucson: Univ. Arizona Press), 348 1997, Icarus, 127, 290

2000, Space Sci. Rev., 92, 295

Weidenschilling, S. J., \& Cuzzi, J. 2005, in Meteorites and the Early Solar System II, ed. D. Lauretta, L. A. Leshin, \& H. Y. McSween, Jr. (Tucson: Univ. Arizona Press), in press

Wood, J. A. 1998, ApJ, 503, L101

Woolum, D. S., \& Cassen, P. 1999, Meteoritics Planet. Sci., 34, 897

Yu, Y., Hewins, R. H., Clayton, R. N., \& Mayeda, T. K. 1995, Geochim. Cosmochim. Acta, 59, 2095

Yurimoto, H., Ito, M., \& Nagasawa, H. 1998, Science, 282, 1874

Yurimoto, H., Koike, O., Nagahara, H., Morioka, M., \& Nagasawa, H. 2000, in Lunar and Planetary Science XXXI (Houston: Lunar Planet. Inst.), No. 1593 Yurimoto, H., \& Kuramoto, K. 2004, Science, 305, 1763 